\title{
Design and Development of Enhanced Exam Hall Seating Arrangement Automation System
}

\author{
A.H.Nandhu Kishore ${ }^{1, *}$, A.Sasireka ${ }^{2}$, K. Vijay ${ }^{3}$ \\ ${ }^{1}$ Associate Professor, Department of Computer Science and Engineering \\ ${ }^{2}$ Assistant Professor, Department of Mathematics \\ ${ }^{1,2}$ PSNA College of Engineering and Technology, \\ Dindigul, Tamil Nadu, India - 624622. \\ ${ }^{3}$ Assistant Professor, Department of Computer Science and Engineering, \\ ${ }^{3}$ Rajalakshmi Engineering College, Chennai, Tamil Nadu, India - 600010 \\ e-mail:ahnkme.psna@gmail.com ${ }^{1, *}$, sasireka.psna@gmail.com ${ }^{2}$,vijay.k@ rajalakshmi.edu.in ${ }^{3}$
}

\begin{abstract}
During exam period, it is very hectic task to find out the venue of the examination hall and which seat is allocated to a particular student. Students used to face many problems for finding the exam hall and their seats.
\end{abstract} Therefore, an exam hall seating arrangement system is needed to computerize the traditional way of preparing the examination hall allotment and generate the hall seating arrangement plan automatically for smooth conduction of exams. The proposed system will guide the students to find out their respective examination hall during their exams. This would also show the respective seat of a student in a particular row of their examination. The other objective of developing this system is to help the students to direct them to their respective examination hall without delays for going on searching for hall plan and their seat allotment. It contains the student, department, subject, staff details, examination hall and their seat allotment. This system will also send the hall number and seat allotted to a particular student through that student's registered email id. The classifier algorithm is used for efficient generation of seating arrangement and Advanced Encryption System (AES) algorithm is used for password verification of registered users for ensuring high-level security
Keywords- exam hall allotment; seat allocation; email notification

Mathematical Subject Classification: 68-04, 68M25, $68 \mathrm{U} 35$

\section{Introduction}

Every institution has examinations held at particular intervals. In every universities or colleges, the exam seats are manually distributed based on some basic rules which are time consuming tasks. A software application is necessary for the exam cell staff members to manage and handle the examination processes in educational institutions during the time of examinations. It must help the students to easily find out the examination hall and the seat allotted to them. This application must be overall controlled by exam coordinator or an administrator.

The software system should automatically generate the exam seat arrangement for every student in the college who are appearing for exams and it must also help the students to know about their exam hall and seating arrangement before the exam in their individual mail with hall number and seat number so that students can identify the respective hall without any delay. The security of the system is also one of the important factors that must be taken into account when designing this software. 


\section{Literature Survey}

The conventional examination hall seat allotment is a mammoth task of manually allocating the seats for conducting the examination. There is a general grievance that government offices have surplus work load but the speed of efficiency in completing the tasks is very low. A software application is necessary to decrease our manual work time. The system must be user-friendly for the fast retrieval and storing of data. It has to be maintained efficiently with the graphical user interface and effective database design [1] [2]. The Image Processing can be done by using camera which recognizes the face of the students. The comparison is done once the face of the student is recognized for security [3].

All the data required for generating the hall plan has to be entered into the computer and reports can be generated automatically so that work will be very easy because there is no need to keep data more on papers. User can generate the report and printed if necessary at the time of conducting the exams [4].

Examination hall seating arrangement application is developed for the colleges to simplify the work of allocating exam halls and issuing hall tickets to the students during exams. It also facilitates to access the examination details of a particular student in a particular department. The information is sorted alphabetically and will be given by the exam cell to the teachers for conducting the exams. This system helps in finding the examination hall details of a student belonging to a particular department [5].

The android and web based application are available to manage and handle the operations in an educational institute during the time examinations. It is an application that can be used by all the students and staff in an educational institute in order to facilitate the communication between them. The application is easily adaptable as it is used on a desktop systems and mobile device [6]. Reports like seating arrangements can be easily generated so that user can generate the report as per the requirement and their wish for the duration of month or the day but not in the middle of the session [7] [8].

Even though the existing literatures reported on various automatic exam hall seating arrangement systems, there are still various issues exist in terms of efficiency and security. Therefore, an enhanced examination hall seating arrangement system is proposed that would automatically generate the exam seat arrangement for the students using an efficient classification algorithm for exam hall scheduling. This system works much better and is efficient than the existing systems by enhancing the security by implementing AES algorithm for registered users' password verification and secured storage in database which is one of the novelty integrated in the proposed work to ensure high level security of the system. It also aims to help the students to know about the exam hall and seating arrangement before the exam begins through their email. The proposed system requires very less paper work. The system mainly focuses on the minimum use of the chair, staying away from students to prevent fraud (copy from others) in the exam by avoiding the overlap of nearby chairs and finally the seat for the students.

\section{Technology Stack}

\section{A. Xampp Server}

XAMPP is an abbreviation for cross-platform including Apache, My SQL, PHP and Perl. Xampp server is used in our system that allows to build Word Press site offline on a local web server on a computer. This simple and lightweight solution works on Windows, Linux, and Mac OS.

\section{B. Languages}

PHP is used for front end development to create web pages in our system. PHP 7, the latest stable release is used for server side scripting as it is a powerful tool for making dynamic and interactive Web pages. MySQL database system is used for back end purposes in our proposed system. It is chosen because it is the most popular Open Source 
Relational SQL Database Management System. MySQL is the most popular database system that can be connected effectively with PHP. The data in MySQL database are stored in the form of tables.

CSS (Cascading Style Sheet) is used for styling the HTML document to describe how HTML elements should be displayed. Cascading Style Sheets (CSS) is a simple mechanism for adding style to Web documents. HTML is the standard markup language used for designing Web pages. HTML is used to create our own Website. Each page contains a series of connections that helps to navigate to other pages using hyperlinks. It defines the meaning and structure of the web content.

\section{Proposed System}

Usually the students face many problems in finding out the exam hall and their seats allotment. Due to the delays in searching of the examination venue, the students get perplexed and create unnecessary stress in them which might make them to perform poor in the exams. An enhanced exam hall seating arrangement automation system is designed and developed for the colleges to simplify the process of allotting the examination hall and seats to the students for smooth conduction of exams. The purpose of developing such a system is to automate the traditional way of conducting the exams. Another objective for developing this software is to generate the seating arrangement report automatically. This system will send hall number and seat allotted to a particular student through student's email id. It facilitates the students to access the examination hall information prior to their exams. The newly invented concept incorporated in the proposed system can aid the students for checking their exam halls in advance. This helps them to identify the floor or get directions to their respective halls without any delays.

\section{Admin Login Module}

The User-Interface is used to access the user's personal information. These data are stored in form of tables using MySQL database. The admin needs to enter their username and password. Validation and verification are performed at the back end. If the given credentials are correct the admin successfully login to the system.

\section{Admin Module}

Admin can able to add the student, staff, and department, subject details and also admin could schedule the halls for the exam. Through this window admin could allocate each staff to a particular hall and allocate students belonging different departments to the respective halls for the exam. Admin will get the updates from the staff regarding the emergency leaves they needed on the day of exam in which they are scheduled for. So admin could reallocate another staff for that exam as hall invigilator.

\section{E. Staff Module}

In this module, staff could see their registered details and they are able to update the profile details. Today's schedule gives the current day's schedule details for the particular staff and they can able to view their daily exam hall details Schedule list module helps to view the full schedule of the staff in that period of exams. Through this module, staff could see the dates and hall details of the exams.

\section{F. Student Module}

In this module, the student can get the exam hall and seat number notification through their personal email id, so that the student will easily find their examination hall without any delay.

\section{Low Level and High Level Design}

Modular design approach is followed in our system to subdivide it into smaller parts called modules that are created independently and then integrated into a single operable system. The proposed system is divided into three modules namely the admin module, staff module and student module. The overall system architecture exhibiting the high level design of the examination hall seating arrangement automation system is shown in Figure 1. The admin module is responsible for adding 


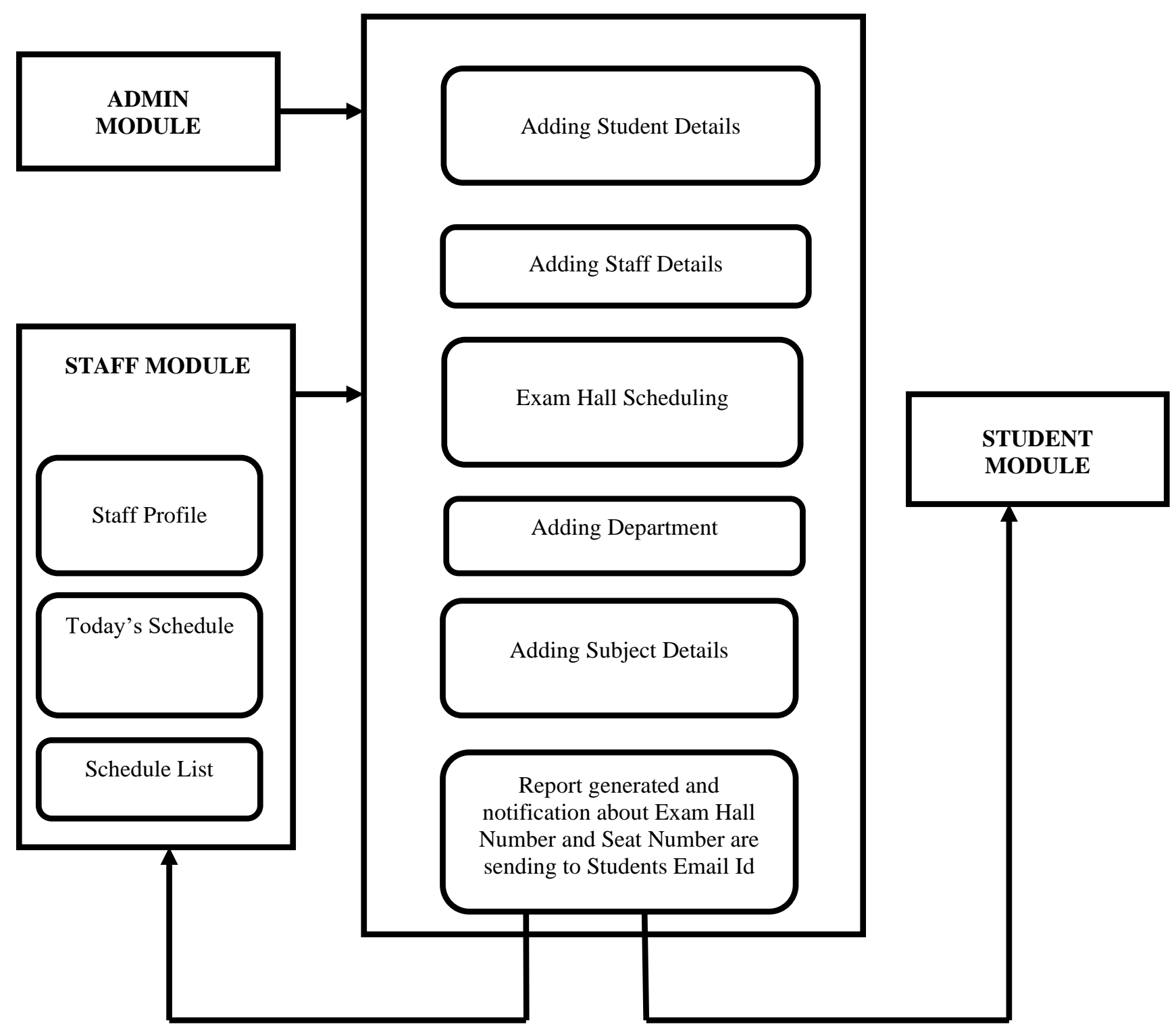

Figure 1. Overall System Architecture

The examination hall seat allotment scheduling and report generation is done using a classifier algorithm to examine the exam hall details, allocate the seats to the students considering their branch so that no two students of same department should be closer to each other as shown in Figure 2. The AES algorithm is employed for password verification and storage in database of the registered users to ensure high-level security of the system. 


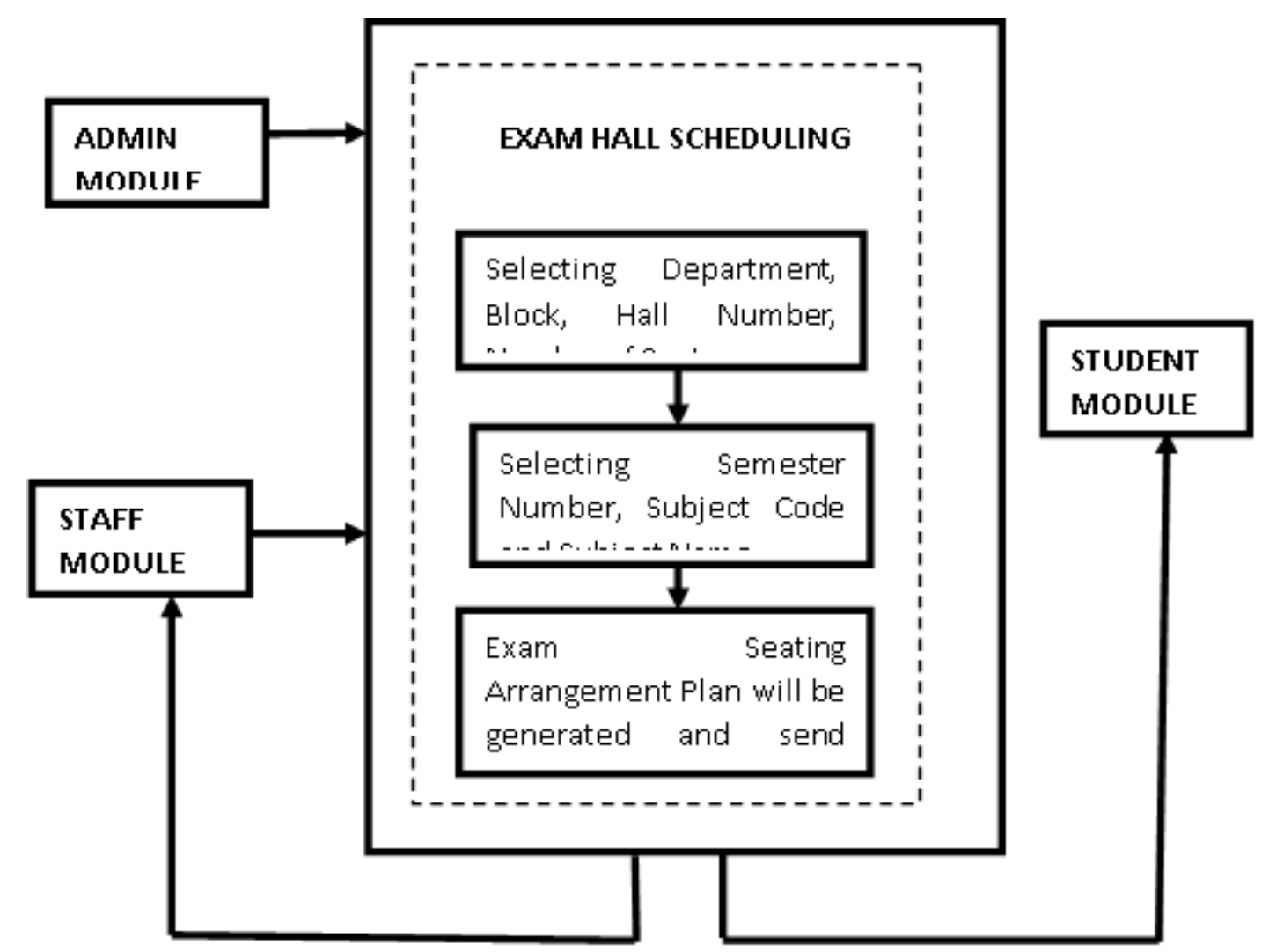

Figure 2. Architectural Design of Exam Hall Seat Allotment Scheduling Module

\section{Results}

This software will be very suitable for the process of examination scheduling because it is not only efficient but also a great method to reduce the manual work. It eases our work load and gives us an accurate measure to resolve seating arrangements and generate the hall plan for conducting the examination. The institutions definitely get benefited by install this software and it can be a great help to them towards the successful conduction of the examinations. The importance of this software is to make our tasks much faster and more reliable. The experiment results of the proposed examination hall seating arrangement automation system are shown through Figure 3 to Figure 7. Figure 7 shows the examination hall seating arrangement plan generated by the proposed system.

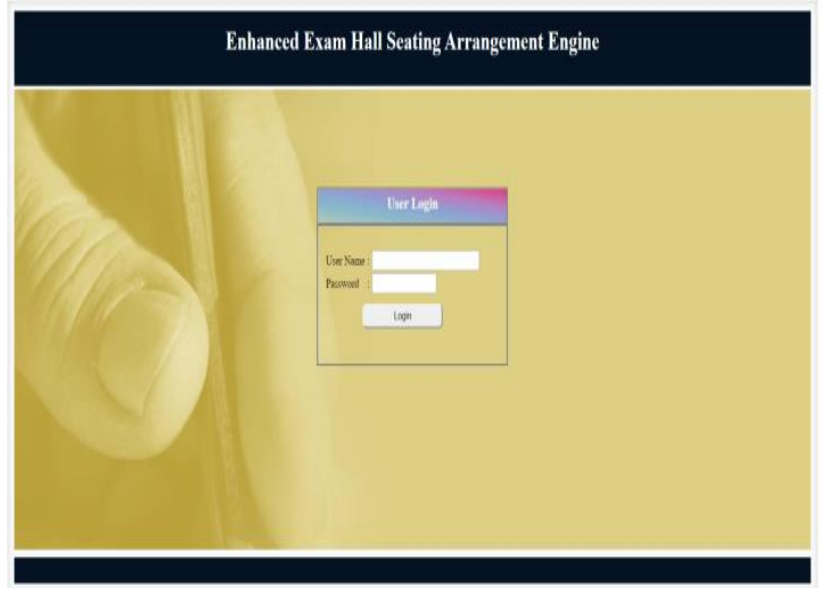

Figure 3. Validation of Admin login 


\section{Department Registration}

$$
\text { Department name : }
$$

Total Year

$$
\text { submit }
$$

\section{Figure 4. Department Registration}

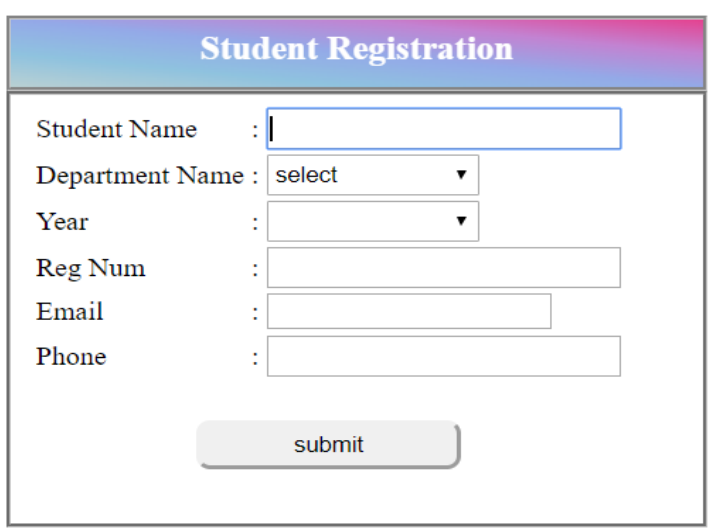

Figure 5. Student Registration

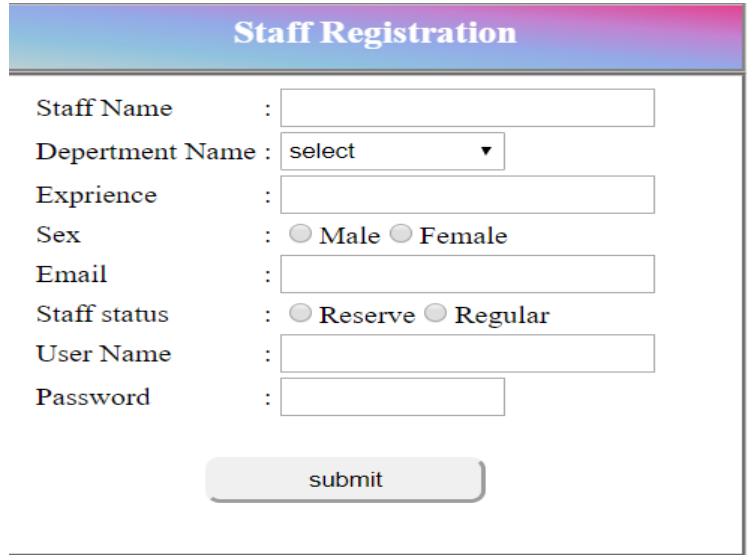

Figure 6. Staff Registration

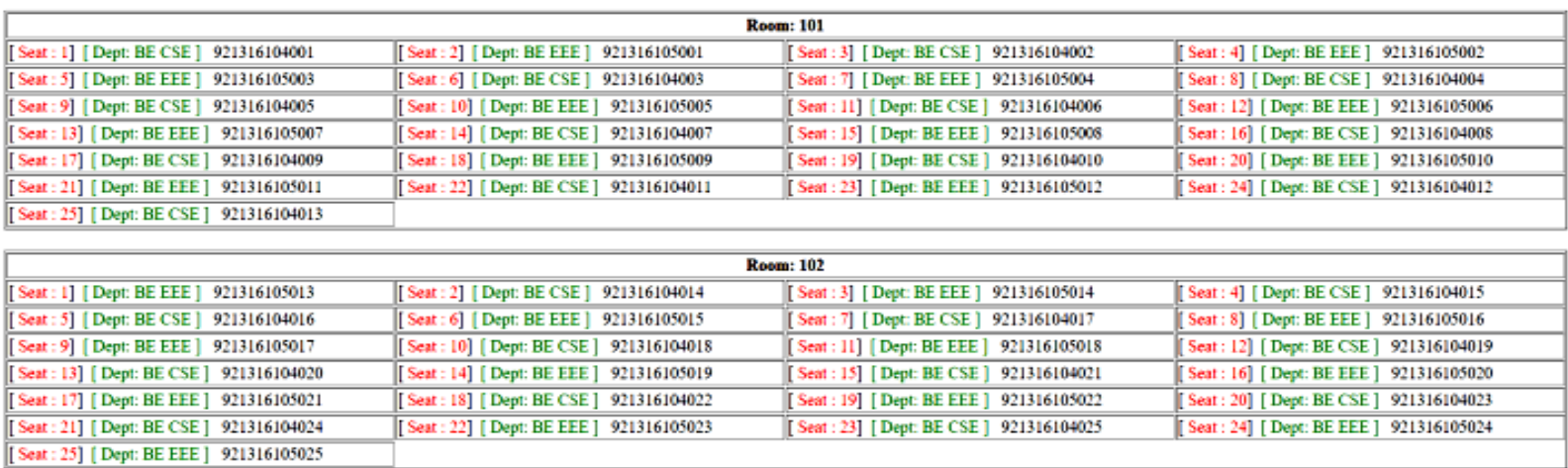

Figure 7. Exam Hall Seating Arrangement Plan 


\section{Conclusion}

Exam hall seating arrangement automation software is developed successfully for the purpose of reducing manual tasks for preparing the hall plan during examinations. This paper presented the efficient seating arrangement plan generation using classification algorithm and ensuring security using AES algorithm. The software application will notify the students and staff about the respective exam hall through their email id. Thus, it reduces the searching time of the examination hall not only for the students but also for the staff members.

\section{References}

[1] Adetona S., Hassan, E., Salawu R. and Omolola S., "The Development of a Web-based Application of Examination Seating Arrangement for Student", ABUAD Journal of Engineering Research and Development, 3(1) (2020), 23-33.

[2] Aravinth S, Pavithra G, Myvizhimalar M, Divya D and Rathinakrithika M, "Exam Hall Seating Arrangement System Using PHP”, International Journal of Innovative Research in Technology, 1(11) (2014), 258 - 261.

[3] Chandra sekar R, Manoj Kumar B, Naveen Selvakumar $\mathrm{R}$ and Tharane Krishna R, "Automation of Hall Seating Arrangement System", International Journal of Innovative
Research in Science, Engineering and Technology, 8(3) (2019), 2278-2283.

[4] Dinesh Chandewar, Mainak Saha, Pushpraj Deshkar and Pankaj Wankhede, "Automatic Seating Arrangement of University Exam", International Journal of Science Technology \& Engineering, 3(9) (2017), 145-149.

[5] R.Gokila and Antony Rohan Dass, "Examination Hall and Seating Arrangement Application using PHP", International Journal of Engineering Science and Computing, 8(2) (2018), 16059- 16065.

[6] Muhammad Ramees C. and Sherin Eliyas K, "Efficient Seat Allocation Process in College Exam System", International Journal for Research in Applied Science \& Engineering Technology, 6(5) (2018), 693-697.

[7] Priya Dharshini S, SelvaSudha $M$ and Anitha lakshmi V, "Exam Cell Automation System",International Journal of Engineering Science and Computing, 7(3) (2017), 80768078.

[8] Vamsi Krishna Yepuri, Gopi Chand Pamu, NaveenKodali and Pradyumna LV "Examination Management Automation System", International Research Journal of Engineering and Technology, 3(2) (2018), 27732779. 